\title{
Sintering of Mixed Powder Compacts in the Fe-C Binary System*
}

\author{
By Kazuhiko Majima**, Yuko Hanatate*** and Hiroyasu Mitani**
}

\begin{abstract}
Three kinds of $\mathrm{Fe}-1.0 \mathrm{wt} \% \mathrm{C}$ binary mixed powder compacts, containing electrolytic, atomized and reduced iron powders with different $\mathrm{H}_{2}$ losses, were used in order to examine the process of carbon diffusion into iron and the decarburization during sintering in a vacuum of $1.3332 \times 10^{-3} \mathrm{~Pa}$, by means of the dilatometric method, measurement of the degree of vacuum, and carbon analysis.

The results obtained are summarized as follows: All of the three kinds of $\mathrm{Fe}-1.0 \% \mathrm{C}$ binary mixed powder compacts showed the expanding (swelling) phenomena after the $\alpha \rightarrow \gamma$ transformation during heating, and the expansion curve in dilatation well agreed with the combined carbon concentration curve. The vacuum measurement revealed that the amount of gas discharge from the specimen with the reduced iron powder was considerably larger than that of the other specimens, while its dilatational expansion was minimum. Therefore it was confirmed that the expanding phenomena did not occur by the gas discharge but by the carbon diffusion into $\gamma-\mathrm{Fe}$.
\end{abstract}

(Received April 18, 1977)

\section{Introduction}

Usually, the sintered carbon steel is produced through the sintering process of mixed powder compacts composed of pure iron and graphite powder in a reducing gas or in an inert gas atmosphere.

Up to the present, many papers ${ }^{(1) \sim(6)}$ have been published on the sintering behavior of the iron and graphite binary mixed powder compacts. It seems very difficult to get the desired amount of combined carbon owing to the reaction between the added graphite and the oxygen contained in iron powder or the gases in the sintering atmosphere. Therefore it is required to clarify the mechanism of the carburization and decarburization process during sintering.

In this experiment, we investigated the process of carbon diffusion into iron in persuit of the sintering behavior of the $\mathrm{Fe}-\mathrm{C}$ binary mixed powder compacts mainly by the dila-

* This paper was published originally in Japanese in J. Japan Inst. Metals, 39 (1975), 168.

** Department of Materials Science and Engineering, Faculty of Engineering, Osaka University, Suita 565, Japan.

*** Graduate School, Osaka University, Suita 565, Japan.

Trans. JIM tometric method, and also clarified the carburization mechanism by carbon analysis and the vacuum measurement in relation to the above-mentioned differential dilatometric experiment.

\section{Experimental Procedure}

The properties of the electrolytic, atomized, reduced iron powder and graphite powder are listed in Table 1. The iron powder and the graphite powder were well mixed in the given proportion, with the addition of $0.3 \mathrm{wt} \%$ glycerin as the lubricant, and compacted at a constant pressure of $6 \mathrm{t} / \mathrm{cm}^{2}$ at room temperature.

The compacts obtained $(5 \mathrm{~mm} \times 5 \mathrm{~mm} \times$ $20 \mathrm{~mm}$ ) were used as the specimens for differential dilatometry, and the 18-8 stainless steel rod of the same dimensions was used as a neutral.

All of the specimens were heated in a vacuum of $1.3332 \times 10^{-3} \mathrm{~Pa}$ at a constant rate of $10^{\circ} \mathrm{C}$ $/ \mathrm{min}$ up to $1150^{\circ} \mathrm{C}$ and cooled down to room temperature at about $30^{\circ} \mathrm{C} / \mathrm{min}$ after isothermal holding for $1 \mathrm{~h}$.

Furthermore, in order to examine the process of carbon diffusion into iron, the analysis of total, combined, and free carbon was carried out by the coulomb metric procedure according

1977 Vol. 18 
Table 1 Characteristics of powders used in this experiment.

\begin{tabular}{|c|c|c|c|c|c|}
\hline Powder & & $\begin{array}{c}\text { Electrolytic } \\
\text { iron }\end{array}$ & $\begin{array}{c}\text { Atomized } \\
\text { iron }\end{array}$ & $\begin{array}{c}\text { Höganäs } \\
\text { iron }\end{array}$ & Graphite \\
\hline \multirow{5}{*}{$\begin{array}{l}\text { Chemical } \\
\text { analysis } \\
(\%)\end{array}$} & C & 0.007 & 0.007 & 0.001 & \multirow{8}{*}{$\begin{array}{l}\text { Carbon } 99.5 \% \\
\text { Ash } \quad 0.5 \%\end{array}$} \\
\hline & $\mathrm{Si}$ & - & 0.01 & 0.01 & \\
\hline & Mn & - & 0.20 & - & \\
\hline & $\mathbf{P}$ & - & 0.009 & 0.05 & \\
\hline & $\mathbf{S}$ & - & 0.010 & 0.05 & \\
\hline \multirow{2}{*}{\multicolumn{2}{|c|}{$\begin{array}{l}\text { Acid insol. }(\%) \\
\text { App. density }\left(\mathrm{kg} / \mathrm{m}^{3}\right)\end{array}$}} & 0.012 & 0.08 & - & \\
\hline & & $2.68 \times 10^{3}$ & $2.99 \times 10^{3}$ & $2.40 \times 10^{3}$ & \\
\hline Flow rate & $(\mathrm{s} / 50 \mathrm{~g})$ & 26.2 & 22.3 & 31.0 & \\
\hline \multirow{5}{*}{$\begin{array}{l}\text { Particle } \\
\text { size } \\
\text { in mesh } \\
(\%)\end{array}$} & $100 \sim 150$ & 23.6 & 21.4 & 19.8 & \multirow{5}{*}{$\begin{array}{l}+300<10 \% \\
-300>90 \%\end{array}$} \\
\hline & $150 \sim 200$ & 29.5 & 22.5 & 30.6 & \\
\hline & $200 \sim 250$ & 16.5 & 9.7 & 19.4 & \\
\hline & $250 \sim 325$ & 17.4 & 19.8 & 18.2 & \\
\hline & $\sim 325$ & 12.8 & 26.6 & 12.0 & \\
\hline \multicolumn{2}{|c|}{$\mathrm{H}$ loss $(\%)$} & 0.05 & 0.15 & 0.25 & \\
\hline
\end{tabular}

to the JID method.

\section{Experimental Results}

The differential dilatometric curves of the $\mathrm{Fe}-\mathrm{C}$ binary mixed powder compacts with $0 \sim 0.8 \% \mathrm{C}$ and $1.0 \sim 3.0 \% \mathrm{C}$ are presented in Fig. 1 and Fig. 2, respectively.

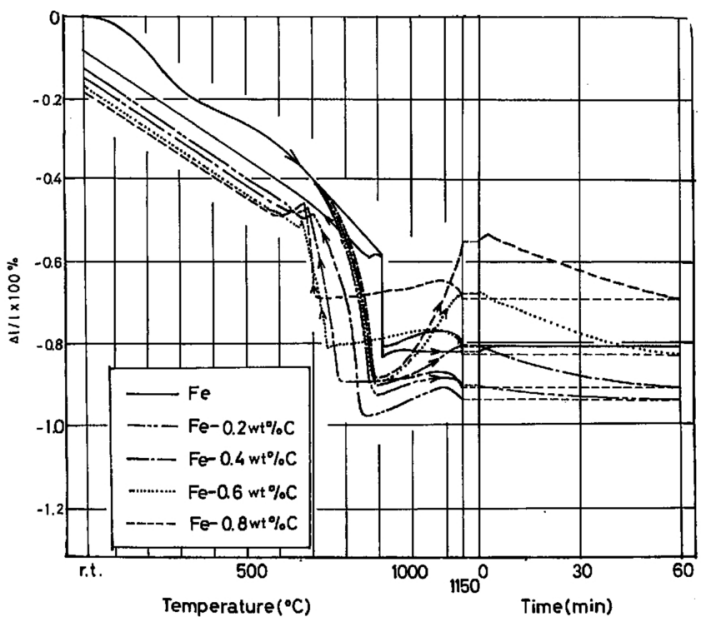

Fig. 1 Differential dilatometric curves of the $\mathrm{Fe}-\mathrm{C}$ binary mixed powder compacts containing up to $0.8 \mathrm{wt} \% \mathrm{C}$, during heating up to $1150^{\circ} \mathrm{C}$ and isothermal holding for $60 \mathrm{~min}$. (Heating rate: $10^{\circ} \mathrm{C} / \mathrm{min}$., Atmosphere: Vacuum, Compacting pressure: $6 \mathrm{t} / \mathrm{cm}^{2},-100$ mesh Electrolytic iron powder used)
The specimen of pure iron compacts shows slight shrinkage by sintering from about $650^{\circ} \mathrm{C}$ during the heating process, followed by rapid contraction due to the $\alpha \rightarrow \gamma$ transformation. In the $\gamma$ region during the heating process after the $\alpha \rightarrow \gamma$ transformation, the shrinkage due to sintering is scarcely noticed.

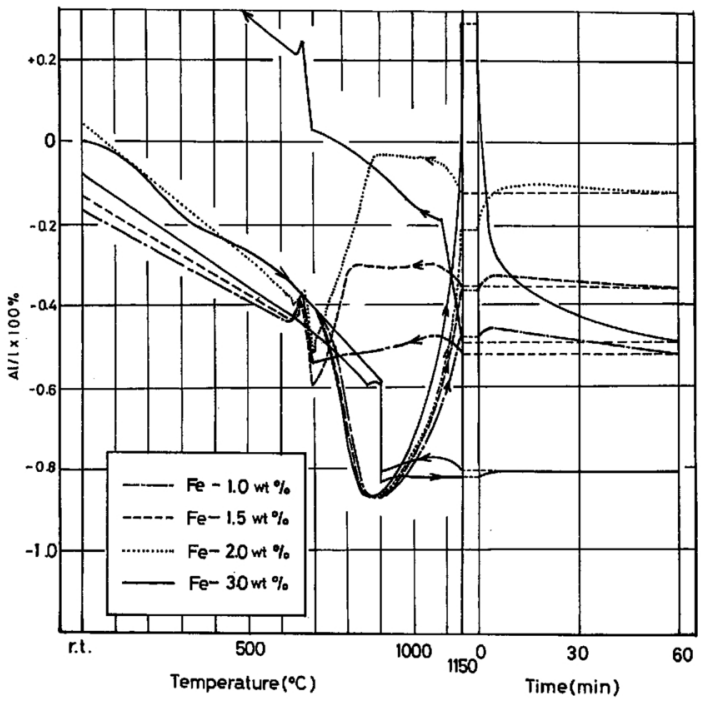

Fig. 2 Differential dilatometric curves of the $\mathrm{Fe}-\mathrm{C}$ binary mixed powder compacts containing more than $1.0 \mathrm{wt} \% \mathrm{C}$, during heating up to $1150^{\circ} \mathrm{C}$ and isothermal holding for $60 \mathrm{~min}$. (Heating rate: $10^{\circ} \mathrm{C} /$ min, Atmosphere: Vacuum, Compacting pressure: $6 \mathrm{t} / \mathrm{cm}^{2},-100$ mesh Electrolytic iron powder used) 
During the cooling process, no remarkable changes, except for the great dip due to the reversible $\gamma \rightarrow \alpha$ transformation, are detected, and the slight shrinkage due to sintering is observed at room temperature.

Even the specimens containing graphite show nearly the same characteristics during the heating process up to $700^{\circ} \mathrm{C}$, while above $700^{\circ} \mathrm{C}$, part of carbon diffuses into $\alpha-\mathrm{Fe}$, and the remarkable contraction due to the transformation lasts till $900^{\circ} \mathrm{C}$. Immediately after the $\alpha \rightarrow \gamma$ transformation, all of the specimens containing graphite begin to expand, where the amount of expansion increases in proportion to the added amount of graphite. Among these specimens, the $\mathrm{Fe}-0.2 \% \mathrm{C}$ specimen begins to shrink from about $1130^{\circ} \mathrm{C}$ during heating, while all of the other specimens keep expanding till $1150^{\circ} \mathrm{C}$.

During isothermal sintering at $1150^{\circ} \mathrm{C}$, the specimens with $0.8 \sim 2.0 \% \mathrm{C}$ keep expanding for the first few minutes, followed by slight contraction, while the specimen with $3.0 \% \mathrm{C}$ begins to contact abruptly at the moment it becomes $1150^{\circ} \mathrm{C}$, which reminds us the liquid phase sintering.

Being subject to the carbon content diffused into iron during heating and isothermal holding, the temperature to initiate the expansion due to the $\gamma \rightarrow \alpha$ transformation during the cooling process becomes lower with increasing amount of graphite, and for the $\mathrm{Fe}-1.0 \% \mathrm{C}$ specimen, it corresponds to the eutectoid temperature.

The specimens with 1.5 and $2.0 \% \mathrm{C}$ contract abruptly from 830 and $890^{\circ} \mathrm{C}$, respectively, owing to the precipitation of $\mathrm{Fe}_{3} \mathrm{C}$, and both of the specimens show expansion from about $700^{\circ} \mathrm{C}$ due to the $\gamma \rightarrow \alpha$ transformation, and for the specimen with $3.0 \% \mathrm{C}$, the expansion due to the solidification of the eutectic liquid starts from $1150^{\circ} \mathrm{C}$ during cooling and is completed by supercooling up to $1100^{\circ} \mathrm{C}$. During cooling below this temperature, there is no prominent change except for the expansion due to the $\gamma \rightarrow \alpha$ transformation.

The $\mathrm{Fe}-1.0 \% \mathrm{C}$ binary sintered structure is shown in Photo. 1, where a homogeneous eutectoid structure is observed. In the $\mathrm{Fe}-2.0 \% \mathrm{C}$ binary sintered structure of Photo. 2 , the pri-

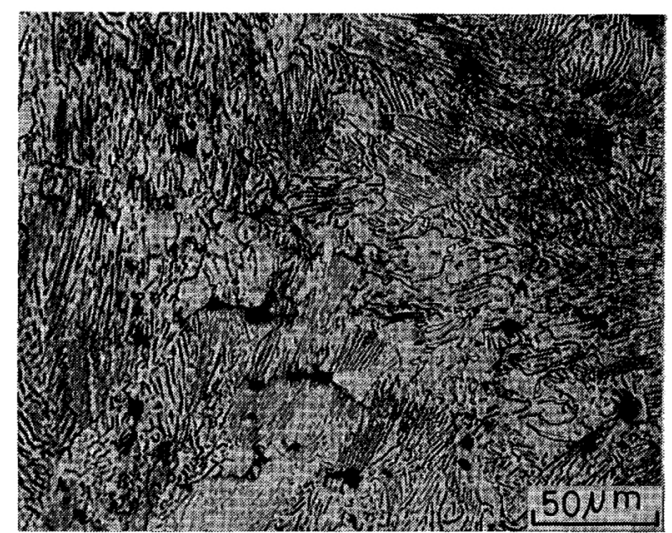

Photo. 1 Microstructure of $\mathrm{Fe}-1.0 \mathrm{wt} \% \mathrm{C}$ binary mixed powder compacts sintered at $1150^{\circ} \mathrm{C}$ for $1 \mathrm{~h}$ in vacuum.

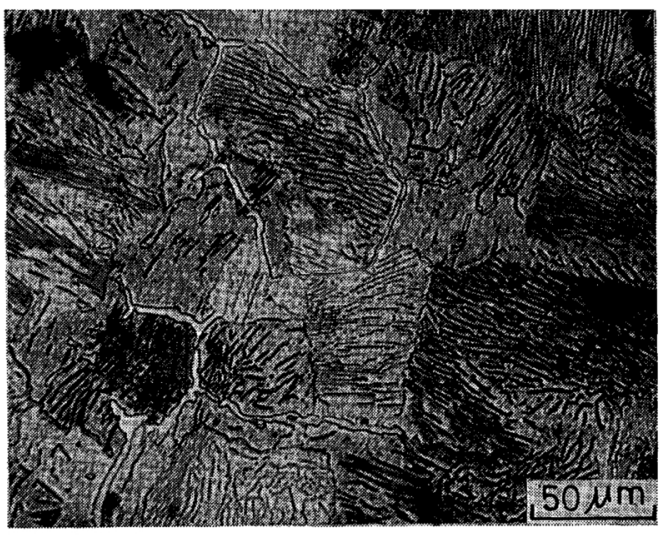

Photo. 2 Microstructure of Fe-2.0 wt \% C binary mixed powder compacts sintered at $1150^{\circ} \mathrm{C}$ for $1 \mathrm{~h}$ in vacuum.

mary precipitated $\mathrm{Fe}_{3} \mathrm{C}$ develops into the grain boundaries like a network, and in the case of the $\mathrm{Fe}-3.0 \% \mathrm{C}$ binary sintered structure, the crysterized graphite due to the eutectic reaction is observed. Anyway, all the above-mentioned microstructures correspond fairly well to the shrinkage process during cooling.

In Fig. 3, the amount of expansion in the $y$ region during the heating process (a), the isothermal shrinkage (b), and the dimensional change at room temperature after sintering, against the added amount of graphite are shown. The amount of expansion observed in the $\gamma$ region increases linearly in proportion to the added amount of graphite, which means that this expansion is related to the carbon 


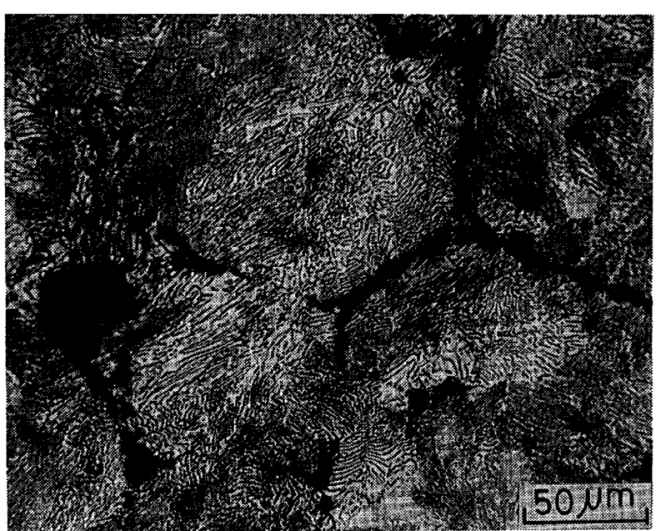

Photo. 3 Microstructure of $\mathrm{Fe}-3.0 \mathrm{wt} \% \mathrm{C}$ binary mixed powder compacts sintered at $1150^{\circ} \mathrm{C}$ for $1 \mathrm{~h}$ in vacuum.

diffusion into $\gamma$ iron.

The amount of the remaining shrinkage at room temperature after sintering at $1150^{\circ} \mathrm{C}$ for $1 \mathrm{~h}$ is maximum at about $0.8 \sim 1.0 \% \mathrm{C}$, which suggests that the rate of graphite addition is most effective in raising the sintered density of the $\mathrm{Fe}-\mathrm{C}$ binary system.

Figure 4 shows the results of carbon analysis of all the specimens used for the abovementioned dilatometric experiment. As to the specimens with less than $1.0 \%$ graphite, the decarburization and the free carbon are extremely little, and in this case, more than $90 \%$ of the added graphite remains as the

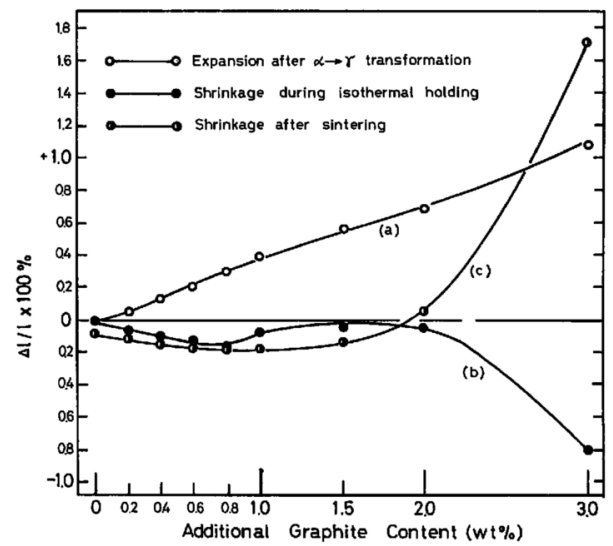

Fig. 3 Dependence of additional graphite content on expansion occurred after the $\alpha \rightarrow \gamma$ transformation (a), shrinkage during isothermal holding at $1150^{\circ} \mathrm{C}$

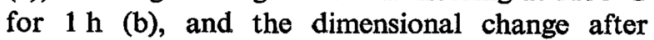
sintering (c). combined carbon. However, for the specimens with more than $1.0 \%$ graphite, the decarburization increases slightly and the amount of free carbon increases remarkably, so the rate of combined carbon becomes lower.

Subsequently, in order to investigate how the carbon diffuses into iron, the carbon analysis is carried out for the representative specimen with $1.0 \% \mathrm{C}$, furnace cooled to room temperature from 900 to $1150^{\circ} \mathrm{C}$, during the heating process under the same condition as mentioned above, and the result is presented in Fig. 5. The rate of total carbon is about $95 \%$ of the added graphite, and the rate of decarburization is about $5 \%$ for the specimens cooled from the temperatures lower than $1100^{\circ} \mathrm{C}$ while on the specimen cooled from $1150^{\circ} \mathrm{C}$, their rates becomes 93 and $7 \%$, respectively. On the other hand, the rate of combined carbon increases from 0.15 to $0.82 \%$ with increasing temperature from 900 to $1150^{\circ} \mathrm{C}$, and it is to be noted that the curve of combined carbon corresponds fairly well to the differential dilatometric curve mentioned above.

From the differential dilatometric curves of the $\mathrm{Fe}-1.0 \% \mathrm{C}$ binary mixed powder compacts with various particle sizes of electrolitic iron powder, the total amount of expansion is represented as the height from the bottom of

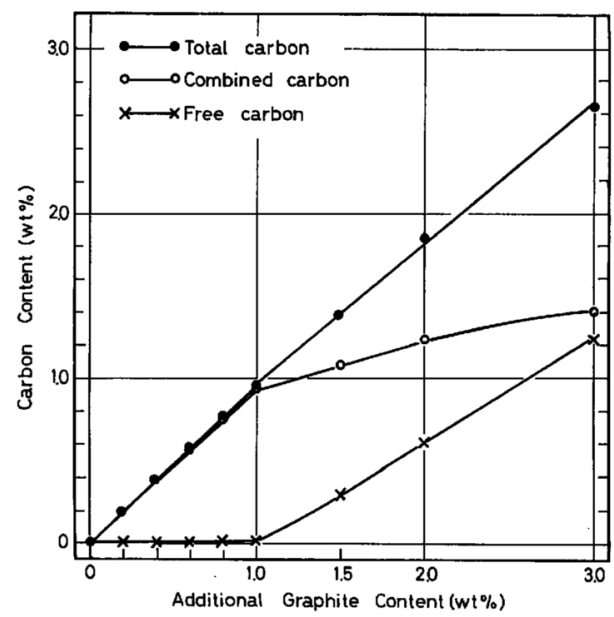

Fig. 4 Concentration curves of the total carbon, combined carbon and free carbon of the $\mathrm{Fe}-\mathrm{C}$ binary mixed powder compacts sintered at $1150^{\circ} \mathrm{C}$ for $1 \mathrm{~h}$. 


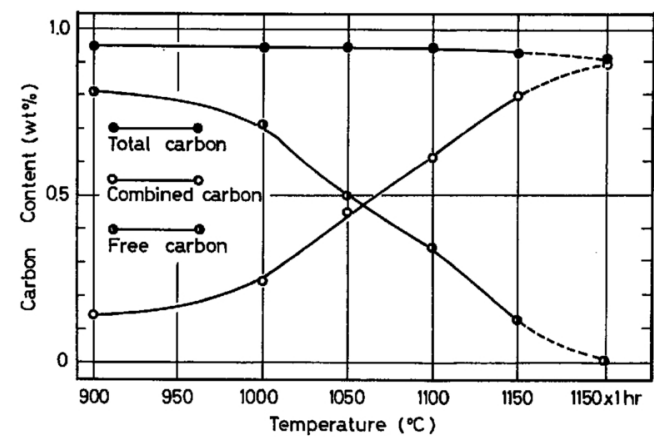

Fig. 5 Concentration curves of the total carbon, combined carbon and free carbon for the $\mathrm{Fe}-1.0$ wt $\% \mathrm{C}$ binary mixed powder compacts furnace cooled from the given temperature during heating up to $1150^{\circ} \mathrm{C}$ and after isothermal holding at $1150^{\circ} \mathrm{C}$ for $1 \mathrm{~h}$.

the shrinkage in the vicinity of $900^{\circ} \mathrm{C}$ to the top of the expansion and the dimensional changes during isothermal holding are presented as a histogram in Fig. 6 against the particle size.

The specimen with a large particle size of electrolytic iron powder does not fully expand even at $1150^{\circ} \mathrm{C}$ during the heating process, and the expansion continues until isothermal holding. However, as the particle size becomes smaller, the rate of expansion increases. Consequently, the amount of the residual expansion during isothermal holding decreases, and the

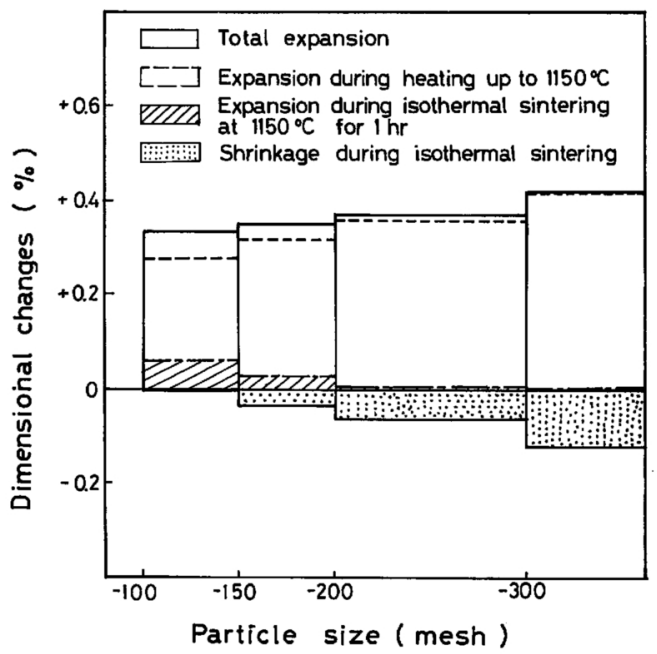

Fig. 6 The influence of the particle size on the dimensional changes during sintering of the $\mathrm{Fe}-1.0 \mathrm{wt} \% \mathrm{C}$ binary mixed powder compacts. shrinkage due to isothermal sintering increases inversely.

From the above-mentioned result, it is obvious that the expansion observed from about $900^{\circ} \mathrm{C}$ during the heating process is affected by the particle size of iron powder. Therefore, the following differential dilatometric experiment of three kinds of $\mathrm{Fe}-$ $1.0 \mathrm{wt} \% \mathrm{C}$ binary mixed powder compacts, containing electrolytic, atomized, and reduced iron powder with different $\mathrm{H}_{2}$ loss ${ }^{(7)}$, was carried out by using the same particle size of $-150+200$ mesh iron powder, and the result is shown in Fig. 7. Moreover, the result of a vacuum measurement and the result of carbon analysis related to Fig. 7 are presented in Fig. 8 and Fig. 9, respectively. In the first place, according to the differential dilatometric

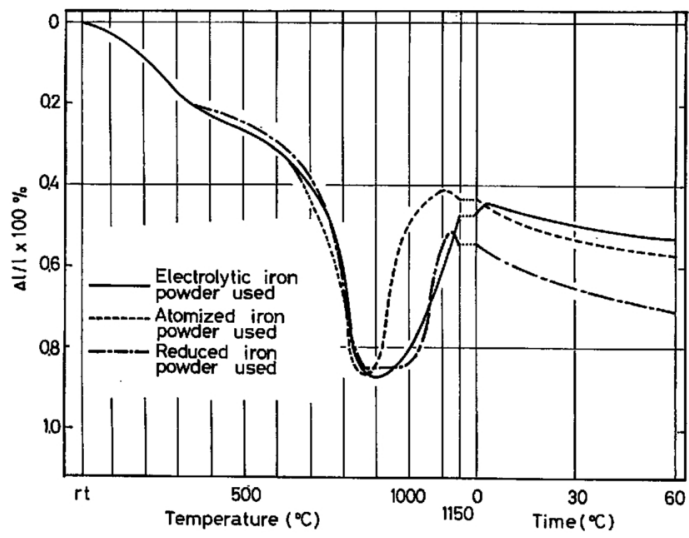

Fig. 7 Differential dilatometric curves for the $\mathrm{Fe}-1.0$ wt $\% \mathbf{C}$ binary mixed powder compacts with three kinds of iron powder during heating up to $1150^{\circ} \mathrm{C}$ and isothermal holding at $1150^{\circ} \mathrm{C}$ for $1 \mathrm{~h}$.

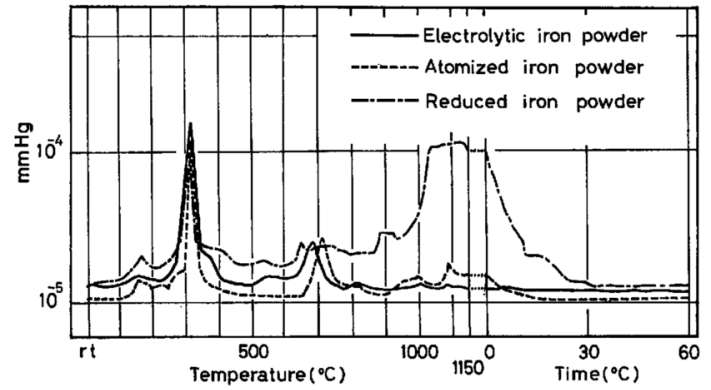

Fig. 8 Variation of vacuum for the $\mathrm{Fe}-1.0 \mathrm{wt} \% \mathrm{C}$ binary mixed powder compacts with three kinds of iron powder, during heating up to $1150^{\circ} \mathrm{C}$ and jsothermal holding at $1150^{\circ} \mathrm{C}$ for $1 \mathrm{~h}$. 


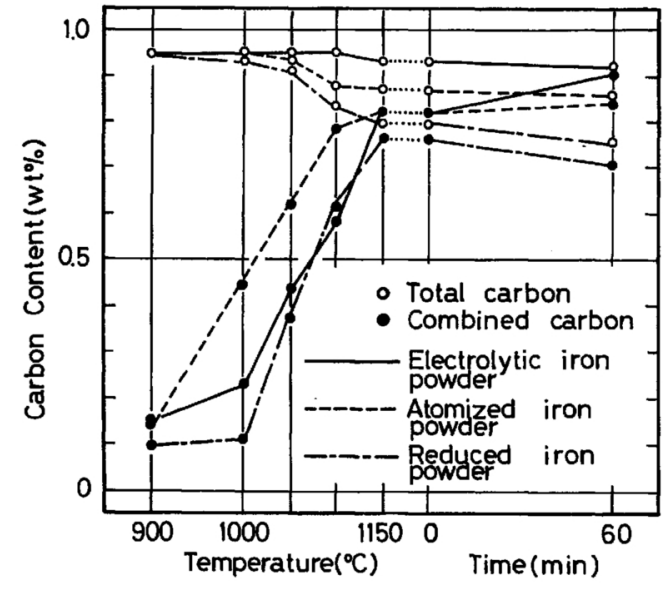

Fig. 9 Concentration curves of the total carbon, combined carbon for the $\mathrm{Fe}-1.0 \mathrm{wt} \% \mathrm{C}$ binarymixed powder compacts with three kinds of iron powder furnace cooled from the given temperature during heating up to $1150^{\circ} \mathrm{C}$ and after isothermal holding at $1150^{\circ} \mathrm{C}$ for $1 \mathrm{~h}$.

curves in Fig. 7, all of the three specimens show nearly the same tendency until the $\alpha \rightarrow \gamma$ transformation is complete at about $900^{\circ} \mathrm{C}$. Among them, the two specimens with the electrolytic and atomized iron powder begin to expand immediately after $900^{\circ} \mathrm{C}$, while the specimen with reduced iron powder does not begin to expand till it becomes $1000^{\circ} \mathrm{C}$. In this case, the specimen with electrolytic iron powder continues expanding for the first few minutes during isothermal holding at $1150^{\circ} \mathrm{C}$. On the other hand, the specimen with the atomized iron powder and the specimen with the reduced iron powder show the maximum expansion at 1100 and $1130^{\circ} \mathrm{C}$ respectively, followed by a slight shrinkage.

From the above results, it can be concluded that the rate of expansion is the slowest in the case of the electrolytic iron powder specimen, and the amount of expansion is the smallest in the case of the reduced iron powder specimen.

According to the vacuum measurement accompanied by the differential dilatometric procedure, as shown in Fig. 8, the first sharp peak is noticed at about $300^{\circ} \mathrm{C}$ due to the vaporization of glycerin $^{(8)}$ added as the lubricant, and the second small peak is observed at about $700^{\circ} \mathrm{C}$ nearly equivalent to the $\mathrm{Fe}-\mathrm{C}$ binary eutectoid temperature. With respect to the two specimens with electrolytic or atomized iron powder, the gas discharge decreases abruptly from $750^{\circ} \mathrm{C}$ during heating, while the specimen with reduced iron powder continues the discharge of gas above $700^{\circ} \mathrm{C}$, and especially from 900 to $1000^{\circ} \mathrm{C}$, the amount of the gas discharge increases abruptly. Judging from the above-mentioned results, it seems unlikely that these tendencies correspond to the expanding phenomenon in the differential dilatometric curves mentioned above.

Comparing the three different curves of combined carbon in Fig. 9, the amount of combined carbon for the specimen with reduced iron powder scarcely increases up to $1000^{\circ} \mathrm{C}$, followed by a linear increment from 1000 to $1150^{\circ} \mathrm{C}$, while in the specimen of atomized iron powder, it increases linearly from 900 to $1100^{\circ} \mathrm{C}$ and is retarded above $1100^{\circ} \mathrm{C}$. Though the curve for the specimen of electrolytic iron powder is somewhat similar to that of the reduced iron powder mentioned above, the increment of the combined carbon from 900 to $1000^{\circ} \mathrm{C}$ is higher than that of reduced iron powder, and the concentration rate of combined carbon at $1150^{\circ} \mathrm{C}$ is nearly the same as that of atomized iron powder. These tendencies compare well with the expanding phenomena in Fig. 7, and consequently the expanding phenomenon is closely related to the carbon diffusion into iron.

The total carbon at $900^{\circ} \mathrm{C}$ during heating is about $95 \%$ of the added graphite for all of the three specimens. The decarburization starts from $1000^{\circ} \mathrm{C}$ during the heating process, and it is noticed that the decarburization occurs more easily as the value of $\mathrm{H}_{2}$ loss becomes higher in the order of electrolytic, atomized, and reduced iron powders.

The experiments mentioned above are carried out in vacuum, while the $\mathrm{H}_{2}$ gas is usually used as the sintering atmosphere. So, in the following the same experiments as mentioned above is carried out in $\mathrm{H}_{2}$ gas with a dew point of $-50^{\circ} \mathrm{C}$ using electrolytic iron powder, and the results obtained are shown in Fig. 10 and Fig. 11, respectively.

From the differential dilatometric curves 


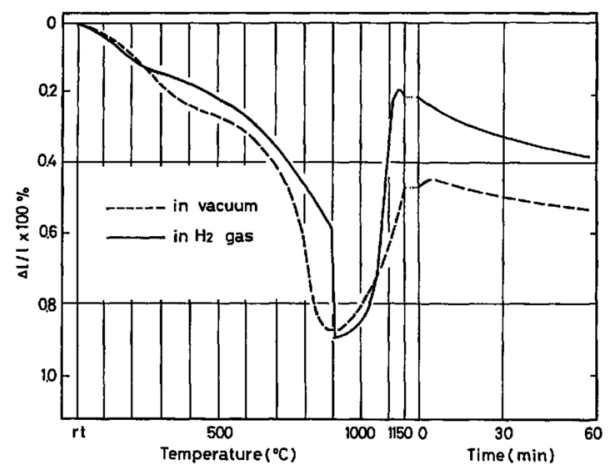

Fig. 10 Differential dilatometric curves for the $\mathrm{Fe}-$ $1.0 \mathrm{wt} \% \mathrm{C}$ binary mixed powder compacts during heating up to $1150^{\circ} \mathrm{C}$ and isothermal holding at $1150^{\circ} \mathrm{C}$ for $1 \mathrm{~h}$ in $\mathrm{H}_{2}$ gas or vacuum $(-150+200$ mesh electrolytic iron powder used).

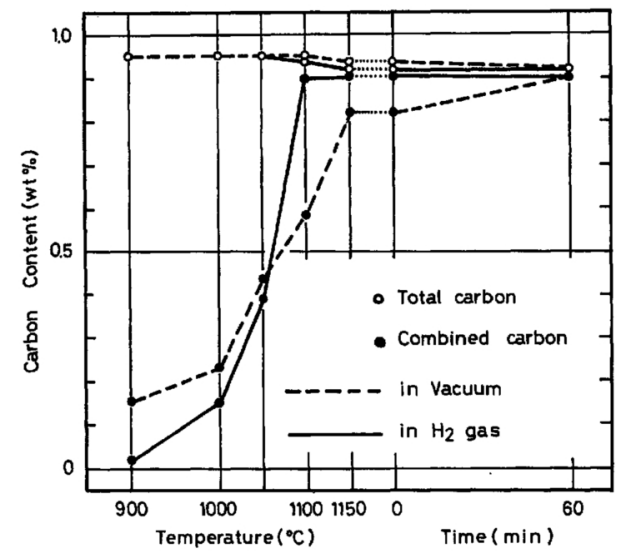

Fig. 11 Concentration curves of the total carbon, combined carbon for the $\mathrm{Fe}-1.0 \mathrm{wt} \% \mathrm{C}$ binary mixed powder compacts furnace cooled from the given temperature during heating up to $1150^{\circ} \mathrm{C}$ and after isothermal holding at $1150^{\circ} \mathrm{C}$ for $1 \mathrm{~h}$, in $\mathrm{H}_{2}$ gas or vacuum.

in Fig. 10, it is acknowledged that the amount of expansion observed from $900^{\circ} \mathrm{C}$ during heating in $\mathrm{H}_{2}$ gas atmosphere is larger, and its slope becomes sharper than that in the case of vacuum sintering.

According to the carbon analysis in Fig. 11, the rate of combined carbon is nearly $0 \%$ at $900^{\circ} \mathrm{C}$ during heating in $\mathrm{H}_{2}$ gas atmosphere, whereas above $900^{\circ} \mathrm{C}$ it increases sharply and shows a maximum value of $0.89 \%$ at $1100^{\circ} \mathrm{C}$. On the other hand, the rate of combined carbon in vacuum is $0.58 \%$ at $1100^{\circ} \mathrm{C}$ and becomes barely $0.82 \%$ at $1150{ }^{\circ} \mathrm{C}$; it shows a maximum value of $0.88 \%$ after isothermal sintering at $1150^{\circ} \mathrm{C}$ for $1 \mathrm{~h}$. There is almost no difference in the total amount of carbon between the two cases.

It should be noted that the above relationships fairly well correspond to the tendencies in the differential dilatometric curves.

\section{Discussion}

As the affinity between amorphous carbon and oxygen is strong and its active surface is covered with the adherent oxygen, the diffusion of carbon into iron is hindered. Therefore it is considered that amorphous carbon is inadequate as the additional carbon element ${ }^{(9)}$, and graphite powder is mainly used instead.

Up to the present, it has been generally agreed that the carburization during sintering for the $\mathrm{Fe}-\mathrm{C}$ binary mixed powder compacts is not carried out by the diffusion through the contact surface between iron and graphite, but mainly through the gas medium of $\mathrm{CH}_{4}$ or $\mathrm{CO}$ produced by the reaction between graphite and oxygen or hydrogen. Therefore it is confirmed that the carburization is not carried out during vacuum sintering ${ }^{(10)}$.

However, according to the present work carried out in a vacuum of $1.3332 \times 10^{-3} \mathrm{~Pa}$, more than $90 \%$ of added graphite diffuses into iron, as shown in Fig. 4.

Though we omit the data on account of the limited space according to the sintering in a vacuum of $1.3332 \sim 1.3332 \times 10^{-1} \mathrm{~Pa}$, it is confirmed that the carburization is unstable and the oxygen in the atmosphere acts as the decarburization element. So it is interpreted that the carburization is carried out directly by the diffusion through the contact surface between graphite and iron powder.

Subsequently, we consider the relation between the expanding phenomenon observed after the $\alpha \rightarrow \gamma$ transformation during the sintering process presented in Fig. 1 and Fig. 2, and the carburization.

The amount of expansion in the $\gamma$ region, as shown in Fig. 3, corresponds to the combined carbon in Fig. 4, while it becomes one-third of the linear expansion coefficient calculated from the increment of the lattice parameter due to carburization, which is considered that owing to the shrinkage due to 
sintering, all of the increment of the lattice parameter due to carburization cannot be converted to the rate of linear expansion.

The curve of combined carbon during heating for the $\mathrm{Fe}-1.0 \mathrm{wt} \% \mathrm{C}$ binary mixed powder compacts in Fig. 5 corresponds to the differential dilatometric curve in Fig. 2 it seems most likely that the expansion observed from $900^{\circ} \mathrm{C}$ during heating is ascribed to carburization.

When we compare the differential dilatometric curves for three kinds of the $\mathrm{Fe}-$ $1.0 \mathrm{wt} \% \mathrm{C}$ binary mixed powder compacts in Fig. 7, containing electrolytic, atomized, and reduced iron powders with different $\mathbf{H}_{2}$ losses, the specimen of atomized iron powder expands rapidly from $900^{\circ} \mathrm{C}$ and its amount is large, while in the specimen of reduced iron powder, the expansion is scarcely noticed from 900 to $1000^{\circ} \mathrm{C}$ and its amount observed from $1000^{\circ} \mathrm{C}$ is small. These processes do not necessarily correspond to the vacuum measurement in Fig. 8 and also to the tendencies of decarburization shown by the curves of total carbon in Fig. 9.

Therefore, it is not necessary to take account of the effect of the gas discharge accompanied with decarburization on the expansion, while the curves of combined carbon in Fig. 9 correspond well to the expanding process in Fig. 7, from which the expansion observed in the $\gamma$ region seems to play an important role as the parameter of carburization.

At the present stage, it cannot be determined whether we have made clear the differences among the three cases mentioned above, and more detailed investigations on the shape, the surface condition and the included gases in iron powders produced by different procedures should be carried out.

At last let us consider the difference between sintering in vacuo and in $\mathrm{H}_{2}$ gas. The conspicuous difference between the two cases, as shown in Fig. 10 and Fig. 11, is that the carburization in the $\alpha$ region slightly proceeds in the former, while it does not take place in the latter. Where $\mathrm{CH}_{4}$ gas scarcely exists in $\mathrm{H}_{2}$ gas sintering, carbon is hardly soluble into $\alpha$ iron, as shown in the $\mathrm{Fe}-\mathrm{C}-\mathrm{H}$ ternary equilibrium diagram ${ }^{(11)}$.
Therefore, even if iron powder came into contact with graphite during heating up to $900^{\circ} \mathrm{C}$ in $\mathrm{H}_{2}$ gas with a dew point of $-50^{\circ} \mathrm{C}$, $\mathrm{CH}_{4}$ gas would not generate and carburization would not proceed at all.

Above $900^{\circ} \mathrm{C}$, iron is reduced by $\mathrm{H}_{2}$ gas, so it is natural that the rate of carburization in $\mathrm{H}_{2}$ gas sintering should be faster than in vacuum.

\section{Conclusion}

Carbon analysis of $\mathrm{Fe}-(0.2 \sim 3.0) \% \mathrm{C}$ binary mixed powder compacts sintered at $1150^{\circ} \mathrm{C}$ for $1 \mathrm{~h}$ in a vacuum of $1.3332 \times 10^{-3} \mathrm{~Pa}$ have revealed that nearly $90 \%$ of the added graphite is obtained as the remaining carbon in all of the specimens, and especially in $\mathrm{Fe}-\mathrm{C}$ binary mixed powder compacts containing up to $1.0 \% \mathrm{C}$, free carbon is scarcely observed. Therefore it is confirmed that the carburization is carried out mainly by the carbon diffusion through the contact surface between iron powder and graphite powder.

All of the three kinds of $\mathrm{Fe}-1.0 \% \mathrm{C}$ binary mixed powder compacts, containing electrolytic, atomized, and reduced iron powders with different $\mathrm{H}_{2}$ losses, showed the expanding phenomena after the $\alpha \rightarrow \gamma$ transformation during heating. Good agreement between the expansion curve in dilatation and the combined carbon concentration curve means that the expanding phenomena is caused by the carbon diffusion into iron.

\section{REFERENCES}

(1) C. G. Goetzel: Treatise in P/M., Vol. II. Interscience Pub. Inc., New York, (1950), 346.

(2) V. A. Dymchenko and Y. F. Morozov: Perspective in P/M., Plenum Press, New York, (1968), p. 293.

(3) R. Chaswick and E. R. Broadfield: Symposium of P/M., Iron \& Steel Inst., Special Rep., No. 38 (1947), 123.

(4) P. ULF Gummenson and A. Stosuy: Tech. Bull. Hoeganaes Corp., (1968), 1.

(5) N. Dantzenberg: Powder Metallurgy International, 3 (1973), 67.

(6) S. M. Kaufman: Powder Metallurgy International, 5 (1973), 11.

(7) JSPM, 3-68: J. Jap. Soc. P/M., 16 (1969), 51.

(8) B. Tamamushi: Physics and Chemistry Dictionary, Iwanami, Tokyo, (1973), p. 363.

(9) P. ULF Gummeson: Perspective in P/M., Vol. 3, Plenum Press., New York, (1968), p. 304.

(10) E. Hayashi and Y. Minamitani: Reports of the Governments Industrial Research Institute, Nagoya, 10, No. 11, (1961), 687.

(11) R. Schenck: Stahl u. Eisen, 46 (1926), 665. 